\title{
Relation of depression with health behaviors and social conditions of dependent community-dwelling older persons in the Republic of Chile
}

\author{
Felipe Alfonso Sandoval Garrido, ${ }^{1,2}$ Nanako Tamiya, ${ }^{2}$ Peter Lloyd-Sherlock ${ }^{3}$ \\ and Haruko Noguchi \\ ${ }^{1}$ Faculty of Political Science and Economics, Waseda University, Tokyo, Japan \\ ${ }^{2}$ Faculty of Medicine, Department of Health Services Research, University of Tsukuba, Tsukuba, fapan \\ ${ }^{3}$ School of International Development, University of East Anglia, Norwich, UK
}

Background: Depressive symptoms are a leading cause of disability and emotional suffering, particularly in old age. However, evidence on depression and old age in developing countries remains largely ignored. The aim of this study was to examine the relation between health behavior and social conditions with depression among dependent community-dwelling older persons in the Republic of Chile.

Methods: This is a cross-sectional and inferential study, using nationally representative secondary data. Two models used logistic regression on 640 dependent community-dwelling older persons from all over Chile, who personally answered a depression assessment, excluding those taking antidepressants. The geriatric depression scale (GDS-15) was used as outcome. The first model aims at any kind of depression (GDS 5>). The second aims at severe depression (GDS $10>$ ). As exposure, we used the health behavior and social conditions of the older persons. Socio-demographic and physical conditions were used as adjustment.

Results: $44.5 \%$ of the older persons presented depressive symptoms. Among them, $11 \%$ had severe depression. Logistic regression showed that significant detrimental factors for being depressed in both models were visiting the doctor five times or over because of acute diseases, feeling uncomfortable with their living arrangement, and feeling discriminated. On the other hand, every additional day of physical exercise and living alone had a beneficial and detrimental effect only in model one.

Conclusion: Analyses on ways to support older persons living alone and the promotion of physical exercise to avoid depression are needed, along with a deeper understanding of the comfort with their living arrangement. Finally, ways to address the discrimination among older persons should be further explored.

Key words: developing countries, Chile, epidemiology, mental health

\section{Introduction}

Depressive symptoms have been reported to be a leading cause of disability among older persons (Whiteford et al., 2013) and to be the most common reason for emotional suffering (Blazer, 2003) among older persons. In old age, depressive symptoms have been shown to have negative effects on the physical health and functioning of the elderly (Comijs et al., 2015), including the quality of life of

Correspondence should be addressed to: Nanako Tamiya, MD, Ph.D. Professor, Department of Health Services Research, Faculty of Medicine, University of Tsukuba, 1-1-1 Tennodai, Tsukuba city, Ibaraki, 305-8575 Japan. Phone and Fax: 81-29-853-8849. Email: ntamiya@md.tsukuba.ac.jp. Received 6 Jan 2016; revision requested 22 Apr 2016; revised version received 16 Jun 2016; accepted 9 Jul 2016. First published online 20 September 2016. those older persons suffering from it (Doraiswamy et al., 2002).

However, evidence, in general, about older persons remains low in developing countries. Scarce evidence has been observed in the Republic of Chile, where it has been argued that there is a fundamental lack of adequate and deep epidemiologic and country-specific research on old age (Gitlin and Fuentes, 2012). This is particularly worrying for Latin America, where the burden of mental illness is a growing concern (Saldivia et al., 2004). Chile has one of the oldest populations in South America (Palloni et al., 2002), with a population aged 60 years and over that reached $14.8 \%$ in 2013 (United Nations Department of Economic and Social Affairs, 2014) and is expected 
to reach $20.11 \%$ by 2025 and $28.2 \%$ by 2050 (Damianovic, 2008).

Depression among older persons aged 60 years and over in Chile has shown to have a prevalence of $23 \%$ for females and $12 \%$ for males (Wong et al., 2005) and was associated with self-perception of health and efficacy, lower instrumental support, and the presence of conflict (Carrasco et al., 2013). However, both studies were limited to the capital city of Chile, Santiago. Both depression (Vicente et al., 2006) and dependency (Gonzalez, 2009) have shown to be different among regions. Dependency has also shown rural-urban and ethnical differences (Gonzalez, 2009). The present study adjusts for these characteristics.

Another study analyzed the relation between depression and age groups in the city of Antofagasta in the northern part of Chile. This study revealed that depression was established in $4 \%$ of a sample ranging from independent to severely dependent older persons (Tapia et al., 2010). However, the design of this study was correlational, but not multivariable, and focalized in a small sample from a different northern region.

The present study builds on the initial report for the survey data presented by the Chilean government (Gonzalez, 2009). In that report, it was mentioned that there exists an association between depression and dependency, adjusted by age, gender, and years of education. In this study, we aim to build a more complex model of interactions focused on the depressive status of dependent older persons, explained by their health behavior and social conditions, while adjusting for physical conditions and sociodemographic covariates.

We hypothesized an association between health behavior and social conditions related to the existence of depressive symptoms of dependent older persons living in the community after adjusting for covariates. This aim of this study is to contribute to building a nation-level body of evidence on the association of depressive symptoms in developing countries, offering a nationally representative rural-urban view, through the random sampling of dependent older persons across the Republic of Chile.

\section{Methods}

A secondary analysis of a nationwide survey data was conducted using a multistage random sampling method. The survey was entitled national survey on the dependency of older persons. The sampling framework method of the original survey, on which this work is based on, was taken from the population and housing census of 2002, and aimed at collecting epidemiological data from persons aged 60 years and over. Stratification was based on rural and urban settings (by population size), and geographical (to include participants from all the regions in Chile). Units of analysis were presented as follows, in ascending order, cities, blocks, and houses. More details on the survey were published elsewhere (Gonzalez, 2009).

The survey on older persons included 4,766 respondents aged 60 years and over. Ninety-one percent of respondents were the older persons themselves, whereas the remaining $9 \%$ were surrogates in case the older persons had some degree of cognitive impairment. The surrogates were individuals with no cognitive impairment. The survey was administered by 126 adults aged 18 years and over, who had previous experiences with complex surveys, and preferably with tertiary education. To minimize bias, PDAs (Personal Digital Assistant) were used to enter the responses. Data collection took place between November 2009 and January 2010.

\section{Participants}

From the initial 4,766 older persons aged 60 years and over, participants with no level of dependency were excluded, for a sample of 1,365 respondents. Furthermore, participants who did not answer the depression assessment (GDS) by themselves (surrogates) were excluded. Additionally, those taking medicines for depression were excluded. Participants on antidepressants may or may not have gone undetected when interviewed using a non-clinical diagnostic tool. A preliminary analyses showed that among those taking anti-depressants and diagnosed by the health staff to be depressed, $28.7 \%$ were not grouped as being depressed using the GDS, whereas the remaining $71.3 \%$ presented some kind of depression. To avoid this uncertainty, we decided to exclude them.

After the exclusion criteria were applied, the final number of older persons was 640 . The sample flowchart can be seen in Figure 1.

The operational definition of dependency for this study follows the one used in the original survey. Dependency was characterized by the functionality of the person and the amount, type, and level of assistance received from others. The two components of this definition were the functional limitation and the need for human assistance because of impaired functionality. Following this general definition of dependent persons, the operational definition includes the following characteristics: bedridden people, people with any level of dementia, an inability to perform one activities of daily living (ADL), inability to perform 


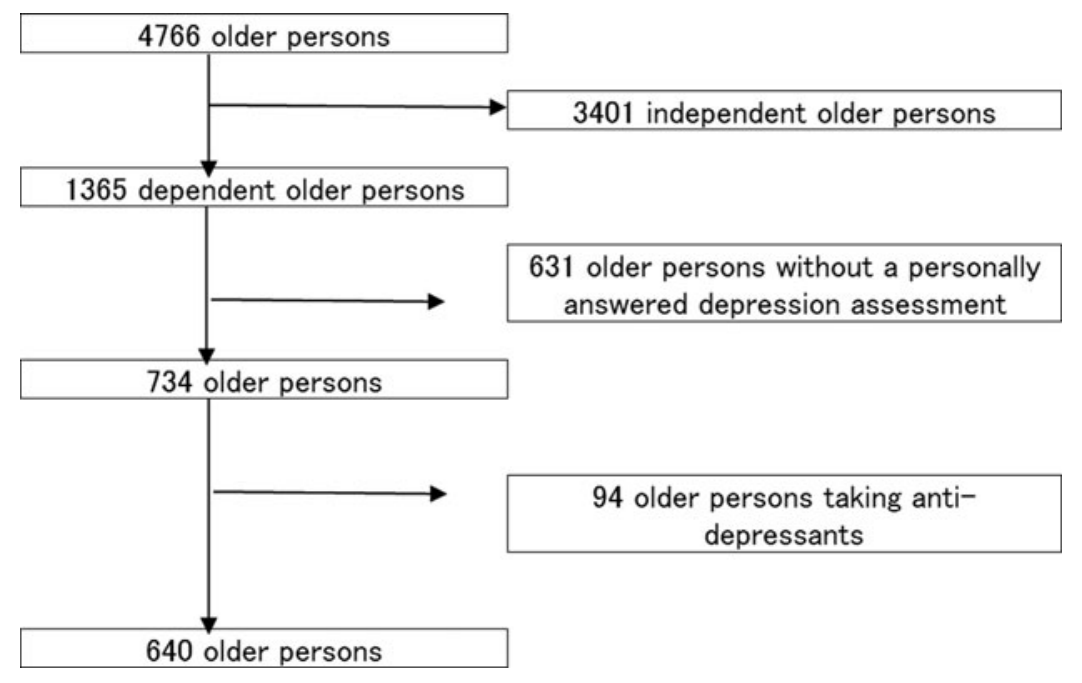

Figure 1. Flowchart of the sample by exclusion criteria. This figure explains visually the process followed from the original population to the final sample.

one instrumental activities of daily living (IADL), in constant need of help to perform one ADL, and those in constant need of help to perform two IADL.

\section{Measurements}

In this study, the outcome was the geriatric depression scale (GDS) (Yesavage et al., 1982). It has been tested and used extensively with older populations (Yesavage et al., 1982). The test used in this study was the short-form GDS that consisted of 15 questions and was developed in 1986 with a high correlation $(\mathrm{r}=0.84, p<0.001)$ with the original 30-item scale (Sheikh, 1986). The cut-off points used in the present study are taken from Almeida and Almeida (1999) where scores over 5 indicated some kind of depression ranging from mild to severe, with a sensitivity and specificity of 85.4 and 73.9, respectively, according to ICD-10. Reliability coefficients were 0.81 (CI $0.73-0.87$ ). In the same study, severe depression was indicated by scores over 10 according to ICD-10 (Almeida and Almeida, 1999). For the present study, two models are presented. In the first model, we focus on any kind of depression. Thus, the depressed group is one with score 6 and over and was coded as one (1). This low cut-off point aimed at a high sensitivity. In the second model, using the same explanatory variables for model consistency, we focused on those considered to be severely depressed. The severely depressed group was one with score 11 and over and was coded as one (1). This high cut-off point aimed at dealing with false-negatives and positives and confirming the findings of the broader definition of the first model. Older persons themselves were required to answer this test; only those answered by the older persons themselves were included in this study.

For this study, two kinds of exposures were set: those related to health behaviors and those related to social conditions. As part of health behaviors, we included the number of visits to the doctor within the past six months were divided into visits due to acute disease or periodic health check-ups. The number of chronic diseases ranged from zero (0) to five (5). The diseases included were: hypertension, Parkinson, diabetes, cardiovascular diseases, and respiratory condition. Smoking presented three options: never smoked, quit smoking, and continued smoking; alcohol drinking was measured at present only with a yes (1) and no (0) option. Physical activity was recorded from the question "In the last three months, how many times a week have you performed physical activities?" The valid range varied from zero (0) to seven (7).

Regarding social conditions, we included living alone was coded as one ( 1 ) and zero (0) when they were living with other persons. Satisfaction with the living arrangement used the variable "Generally speaking, are you uncomfortable living alone/with the persons you live now?" The answer was coded one (1) for yes and zero (0) for no. Unemployment was assessed with the following question "Did you work last week, doing something other than house chores?" and was coded one (1) for yes and zero (0) for no.

Discrimination was taken from the question "Have you felt discriminated in the past 12 months? Never was coded as zero (0) and used as reference, all other kinds of discrimination (socioeconomic 
discrimination, female sex, ethnic background, sexual preferences, foreigner, physical appearance, health conditions, and others) were coded as one (1).

Additionally, to account for covariates and possible confounders, we included both sociodemographic characteristics and physical conditions. Sociodemographics included sex, age, urbanization, ethnic background, education, and marital status of the older persons were included. Also, physical conditions included the Katz Index of activities of daily living (ADL), which measured independence in the care-recipient's ADLs. The six items were rated dichotomously as zero (no) and one (yes), and we calculated a total score (range $0-6)$. Higher scores indicated more independence in ADL.

The Lawton IADL Scale measured independence in IADL. The items were rated dichotomously as zero (no) and one (yes), and we calculated the total score (range 0-8). Higher scores indicated more independence in instrumental ADL.

Falls were registered as a dichotomous variable, in accordance with the answer to the question "In the past 12 months, have you fallen? A fall experience was coded as one (1).

Cognitive impairment was measured using the Mini-Mental State Examination (MMSE). The MMSE is the most commonly used instrument for screening cognitive function. This examination is not suitable for making a clinical diagnosis but could be used to indicate the presence of cognitive impairment. This test had a cut-off point equal or less than 12. Cognitive impairment was coded as one (1) and no-impairment was coded as zero (0).

\section{Statistical methods}

After using descriptive statistics to describe our data in the univariate stage, we looked for correlations between the explanatory variables by using nonparametric Spearman's correlation analysis, where only two sets of variables revealed light correlations $(\rho<0.3)$. Based on the appropriateness of statistical techniques and data for the bivariate relation among each one of the explanatory variables and the primary outcome of depression, we used $\chi^{2}$ with $\Phi$ coefficient for categorical variables and t-test for continuous variables.

Explanatory variables that were entered in the binary logistic regression analysis were those that were frequently mentioned in the literature to have a relation with the depression of older persons and those that had a relation strength in the bivariate analyses within an alpha value of 0.2 of significance (Table 3). The alpha value of 0.2 was an arbitrary level selected for explanatory variables that were candidate for the subsequent multivariate analysis (Mickey and Greenland, 1989). More traditional levels such as 0.05 may fail in identifying variables known to be important (Bursac et al., 2008). Odds Ratios (OR) with 95\% confidence intervals (CI) were reported. Finally, we conducted an analysis of multicollinearity (variance inflation factor of $<10$ ). Data were analyzed using SPSS version 21.

A written consent to analyze this secondary data was obtained from the National Agency for Older People in Chile.

\section{Results}

Nearly $45 \%$ of the older persons presented some degree of depression. In addition, $11 \%$ presented severe depression. A detailed description of sociodemographic characteristics and physical condition of the older persons is presented in Table 1.

The results of the bivariate analyses of depression, the sociodemographic characteristics, and the physical condition of the older persons are detailed in Table 2. Aiming at a final multivariable model, relations within an alpha value of 0.2 of significance (CI of $80 \%$ ) were found for the age of the older person, urbanization status, and ethnic background. Regarding the relation of depression and the physical condition of the older person, we found ADL and IADL scores to be statistically significant. Additionally, feeling pain in the last four weeks, being admitted to a hospital, number of chronic diseases, falls in the past year, and cardiovascular and respiratory conditions were found to be statistically significant. Details can be seen in Table 2.

Regarding our main exposure, we observed that, among health behaviors, visits to the doctor because of an acute disease were significant. In addition, physical activity was significant along with smoking habits. Finally, among social conditions, we observed that living alone, being uncomfortable with the living arrangement, having worked last week, feeling discriminated, having recreational activities and volunteering, had a significant relation with depression. Details can be seen in Table 3.

\section{Multivariable analysis}

We present two successive regression models. The first for any kind of depression and the second only for those severely depressed. The percentage of cases for which the dependent variable was correctly predicted was $71.5 \%$ in model one and $88 \%$ in model two, an improvement over the $57.1 \%$ and $85.3 \%$ of the null models, respectively. Both models 
Table 1. Univariate analysis of depression and independent variables

\begin{tabular}{|c|c|c|c|}
\hline & & $\begin{array}{l}\text { TOTAL } \\
N\end{array}$ & $\%$ \\
\hline \multicolumn{4}{|l|}{ Depressive symptoms } \\
\hline GDS score (possible range $0-15$ ) & Mean $[\mathrm{SD}]$ & 5.8 & 3.9 \\
\hline \multicolumn{4}{|l|}{ GDS for all kinds of depression versus no-depression } \\
\hline Not depressed (0-5) & & 355 & 56 \\
\hline Depression - mild to severe $(6+)$ & & 285 & 45 \\
\hline \multicolumn{4}{|l|}{ GDS for severe depression versus all others } \\
\hline All others - no depression to moderate $(0-11)$ & & 570 & 89 \\
\hline Severe depression $(12+)$ & & 70 & 11 \\
\hline \multicolumn{4}{|l|}{ Sociodemographic characteristics } \\
\hline \multicolumn{4}{|l|}{ Gender } \\
\hline Male & & 243 & 38.0 \\
\hline Female & & 397 & 62.0 \\
\hline \multicolumn{4}{|l|}{ Age } \\
\hline Number of years & Mean $[S D]$ & 76 & [8.7] \\
\hline \multicolumn{4}{|l|}{ Setting } \\
\hline Rural & & 259 & 40.5 \\
\hline Urban & & 381 & 59.5 \\
\hline \multicolumn{4}{|l|}{ Ethnicity } \\
\hline No ethnic background & & 583 & 91.1 \\
\hline Ethnic background & & 57 & 8.9 \\
\hline \multicolumn{4}{|l|}{ Education } \\
\hline Number of years of education & Mean $[S D]$ & 4.3 & [3.4] \\
\hline \multicolumn{4}{|l|}{ Marital status } \\
\hline Married & & 296 & 46.3 \\
\hline Divorced & & 39 & 6.1 \\
\hline Widow/Widower & & 255 & 39.8 \\
\hline Single & & 50 & 7.8 \\
\hline \multicolumn{4}{|l|}{ Physical conditions } \\
\hline \multicolumn{4}{|l|}{ Physical functionality scores } \\
\hline ADL score & Mean $[\mathrm{SD}]$ & 4.2 & [1.1] \\
\hline IADL score & Mean [SD] & 17.9 & [3.8] \\
\hline \multicolumn{4}{|l|}{ Cognitively impaired by the Mini-Mental Test } \\
\hline No & & 568 & 88.8 \\
\hline Yes & & 71 & 11.1 \\
\hline \multicolumn{4}{|l|}{ Pain in the last four weeks } \\
\hline No pain & & 103 & 16.1 \\
\hline Very little & & 61 & 9.5 \\
\hline A little & & 105 & 16.4 \\
\hline Moderate & & 102 & 15.9 \\
\hline Much & & 175 & 27.3 \\
\hline Very much & & 94 & 14.7 \\
\hline \multicolumn{4}{|l|}{ Admitted to a hospital in the past year } \\
\hline No & & 540 & 84.4 \\
\hline Yes & & 99 & 15.5 \\
\hline \multicolumn{4}{|l|}{ Chronic disease } \\
\hline Number of chronic diseases & Mean $[S D]$ & 1.4 & [1.0] \\
\hline \multicolumn{4}{|l|}{ Hypertension } \\
\hline No & & 190 & 29.7 \\
\hline Yes & & 440 & 68.8 \\
\hline \multicolumn{4}{|l|}{ Parkinson } \\
\hline No & & 610 & 95.3 \\
\hline Yes & & 23 & 3.6 \\
\hline \multicolumn{4}{|l|}{ Diabetes } \\
\hline No & & 467 & 73.0 \\
\hline Yes & & 166 & 25.9 \\
\hline
\end{tabular}


Table 1. Continued.

\begin{tabular}{|c|c|c|c|}
\hline & & $\begin{array}{l}\text { TOTAL } \\
N\end{array}$ & $\%$ \\
\hline \multicolumn{4}{|c|}{ Cardiovascular condition } \\
\hline No & & 486 & 75.9 \\
\hline Yes & & 146 & 22.8 \\
\hline \multicolumn{4}{|c|}{ Respiratory condition } \\
\hline No & & 493 & 77.0 \\
\hline Yes & & 137 & 21.4 \\
\hline \multicolumn{4}{|l|}{ Polypharmacy } \\
\hline No & & 378 & 59.1 \\
\hline Yes & & 262 & 40.9 \\
\hline \multicolumn{4}{|l|}{ Falls in the past year } \\
\hline Number of falls & Mean $[S D]$ & 1.2 & [3.2] \\
\hline
\end{tabular}

This table presents the characteristics of the subjects regarding the main outcome and exposures, along with adjusting covariates

were statistically significant at $<0.001$ according to the omnibus tests of model coefficients. Finally, statistically insignificant Hosmer and Lemeshow tests at an alpha level of 0.05 indicate an acceptable goodness of fit for both models.

The logistic regression model one, for any kind of depression, showed that there were six factors with a detrimental effect: much and very much pain, visiting the doctor five or more times because of acute disease, living alone, being uncomfortable with the living arrangement, and feeling discriminated. The same model showed four beneficial effects on depression: age of the older person, higher ADL and IADL scores, and the number of times of physical activity during the week for the past three months.

In the case of model two, using the same explanatory variables, we found that there are six factors with a detrimental effect on severe depression: being in moderate pain, much pain and very much pain, visiting the doctor five or more times because of acute disease, being uncomfortable with the living arrangement, and feeling discriminated. The same model shows three beneficial effects on severe depression: age of the older person, higher IADL scores, and visiting the doctor for a checkup once or twice in the past 6 months.

Detailed statistics on health behavior and social conditions can be found in Table 4 .

\section{Beneficial factors}

In detail, for model one, significant beneficial factors against any kind of depression were every year of age (OR: 0.96, CI: 0.94-0.98); every additional point of ADL score (OR: 0.80, CI: 0.650.98); every additional point of IADL score (OR:
0.93, CI: 0.87-0.99); and every additional day of physical exercise during the week in the past three months (OR: 0.82, CI: 0.69-0.98). For model two, significant beneficial factors against being severely depressed were every year of age (OR: 0.95, CI: 0.92-0.99); every additional point of IADL score (OR: 0.89, CI: 0.82-0.97); and visiting the doctor for a checkup once or twice in the past six months (OR: 0.44, CI: 0.2-0.99), when compared to those who did not attend.

\section{Detrimental factors}

For model one, significant detrimental factors that increased the likelihood of any kind of depression were being in much pain (OR: 2.60; CI: 1.374.94 ) or very much in pain (OR: 2.30; 1.094.87), when compared to those with no pain; visiting the doctor five times or more because of acute diseases (OR: 2.86, CI: 1.09-7.51), when compared to those with no visits; living alone (OR: 2.09,CI: 1.12-4.03) as opposed to living with others; feeling uncomfortable with their living arrangement (OR: 3.67, CI: 1.12$12.04)$ as opposed to feeling comfortable; and feeling discriminated (OR: 2.24, CI:1.38-3.63) as opposed to not feeling discriminated.

For model two, detrimental factors for being severely depressed were being in moderate pain (OR: 4.02; CI: 1.15-14.11), much pain (OR: 3.49; CI: $1.09-11.19$ ) or very much in pain (OR: $5.93 ; 1.72-20.39$ ), when compared to those with no pain; visiting the doctor five times or more because of acute diseases in the past six months (OR: 4.02, CI: 1.31-12.33), when compared to those with no visits; feeling uncomfortable with their living arrangement (OR: 4.54, CI: 1.3115.68) as opposed to feeling comfortable; and 
Table 2. Bivariate analysis of depression and adjusting covariates

\begin{tabular}{|c|c|c|c|c|c|c|c|}
\hline & & \multicolumn{2}{|c|}{ NOT DEPRESSED } & \multicolumn{2}{|c|}{ DEPRESSED } & \multirow[b]{2}{*}{ TOTAL } & \multirow[b]{2}{*}{$P$-VALU } \\
\hline & & $\mathrm{N}$ & $\%$ & $\mathrm{~N}$ & $\%$ & & \\
\hline \multicolumn{8}{|l|}{ Sociodemographic characteristics } \\
\hline \multicolumn{8}{|l|}{ Gender } \\
\hline Male & & 140 & 57.6 & 103 & 42.4 & 243 & 0.393 \\
\hline Female & & 215 & 54.2 & 182 & 45.8 & 397 & \\
\hline \multicolumn{8}{|l|}{ Age } \\
\hline Number of years & Mean (SD) & 77 & 8.5 & 74.82 & 8.8 & 634 & 0.002 \\
\hline \multicolumn{8}{|l|}{ Setting } \\
\hline Rural & & 154 & 59.5 & 105 & 40.5 & 259 & 0.094 \\
\hline Urban & & 201 & 52.8 & 180 & 47.2 & 381 & \\
\hline \multicolumn{8}{|l|}{ Ethnicity } \\
\hline No ethnic background & & 318 & 54.5 & 256 & 45.5 & 583 & 0.133 \\
\hline Ethnic background & & 37 & 64.9 & 20 & 35.1 & 57 & \\
\hline \multicolumn{8}{|l|}{ Education } \\
\hline Number of years of education & Mean (SD) & 4.35 & 3.44 & 4.33 & 3.40 & 613 & 0.942 \\
\hline \multicolumn{8}{|l|}{ Marital status } \\
\hline Married & & 164 & 55.4 & 132 & 44.6 & 296 & 0.921 \\
\hline Divorced & & 21 & 53.8 & 18 & 46.2 & 39 & \\
\hline Widow/Widower & & 140 & 54.9 & 115 & 45.1 & 255 & \\
\hline Single & & 30 & 55.5 & 285 & 44.5 & 50 & \\
\hline \multicolumn{8}{|l|}{ Physical conditions } \\
\hline \multicolumn{8}{|l|}{ Physical functionality scores } \\
\hline ADL score & mean (SD) & 4.38 & 0.94 & 3.93 & 1.2 & 640 & $<0.001$ \\
\hline IADL score & mean (SD) & 18.3 & 3.68 & 17.28 & 3.88 & 640 & $<0.001$ \\
\hline \multicolumn{8}{|c|}{ Cognitively impaired by the Mini-Mental Test } \\
\hline No & & 313 & 55.1 & 255 & 44.9 & 568 & 0.517 \\
\hline Yes & & 42 & 59.2 & 29 & 40.8 & 71 & \\
\hline \multicolumn{8}{|l|}{ Pain in the last weeks } \\
\hline No pain & & 76 & 73.8 & 27 & 26.2 & 103 & $<0.001$ \\
\hline Very little & & 45 & 73.8 & 16 & 26.2 & 61 & \\
\hline A little & & 67 & 63.8 & 38 & 36.2 & 105 & \\
\hline Moderate & & 61 & 59.8 & 41 & 40.2 & 102 & \\
\hline Much & & 73 & 41.7 & 102 & 58.3 & 175 & \\
\hline Very much & & 33 & 35.1 & 61 & 64.9 & 94 & \\
\hline \multicolumn{8}{|c|}{ Admitted to a hospital in the past year } \\
\hline No & & 311 & 57.6 & 229 & 42.4 & 540 & 0.016 \\
\hline Yes & & 44 & 44.4 & 55 & 55.6 & 99 & \\
\hline \multicolumn{8}{|l|}{ Chronic disease } \\
\hline Number of chronic diseases & Mean (SD) & 1.34 & 0.94 & 1.54 & 1.07 & 638 & 0.010 \\
\hline \multicolumn{8}{|l|}{ Hypertension } \\
\hline No & & 112 & 58.9 & 78 & 41.1 & 190 & 0.283 \\
\hline Yes & & 239 & 54.3 & 201 & 45.7 & 440 & \\
\hline Parkinson & & & & & & & \\
\hline No & & 342 & 56.1 & 268 & 43.9 & 610 & 0.435 \\
\hline Yes & & 11 & 47.8 & 12 & 52.2 & 23 & \\
\hline Diabetes & & & & & & & \\
\hline No & & 266 & 57 & 201 & 43 & 467 & 0.311 \\
\hline Yes & & 87 & 52.4 & 79 & 47.6 & 166 & \\
\hline Cardiovascular condition & & & & & & & \\
\hline No & & 278 & 57.2 & 208 & 42.8 & 486 & 0.165 \\
\hline Yes & & 74 & 50.7 & 72 & 49.3 & 146 & \\
\hline Respiratory condition & & & & & & & \\
\hline No & & 289 & 58.6 & 204 & 41.4 & 493 & 0.013 \\
\hline Yes & & 64 & 46.7 & 73 & 53.3 & 137 & \\
\hline
\end{tabular}


Table 2. Continued.

\begin{tabular}{|c|c|c|c|c|c|c|c|}
\hline & & \multicolumn{2}{|c|}{ NOT DEPRESSED } & \multicolumn{2}{|c|}{ DEPRESSED } & \multirow[b]{2}{*}{ TOTAL } & \multirow[b]{2}{*}{$P$-VALUE } \\
\hline & & $\mathrm{N}$ & $\%$ & $\mathrm{~N}$ & $\%$ & & \\
\hline \multicolumn{8}{|l|}{ Polypharmacy } \\
\hline No & & 214 & 56.6 & 164 & 43.4 & 378 & 0.484 \\
\hline Yes & & 141 & 53.8 & 121 & 46.2 & 262 & \\
\hline \multicolumn{8}{|l|}{ Falls in the past year } \\
\hline Number of falls & mean $(\mathrm{SD})$ & 0.87 & 1.75 & 1.5 & 4.41 & 635 & 0.026 \\
\hline
\end{tabular}

feeling discriminated (OR: 3.85, CI:2.04-7.25) as opposed to not feeling discriminated.

\section{Discussion}

In our study, depression, ranging from mild to severe, had a prevalence of $44.5 \%$ among the community-dwelling older persons aged 60 years and over. This figure is much higher than that found in similar studies among old-age communityresidents using the GDS scales. In China the study showed a prevalence of $26 \%$ using the same scale and the same cut-off score among older residents in a Chinese rural community (Liu et al., 1997). In this study, ADL were included as predictors. Also, in Pakistan, the prevalence of depression has been reported to reach $22.9 \%$ in an older population aged 65 years and over, for both dependent and independent communityresidents, according to the GDS-15 (Ganatra et al., 2008). In Mexico, older population aged 60 years and over, for both dependent and independent community residents, according to the 30 -item GDS, depressive symptoms was estimated to be $21.7 \%$ (Garcia-Pena et al., 2008). This suggests that the prevalence of depression in the Republic of Chile may be high. However, it may be considered that ethno-cultural differences may preclude crossnational comparisons regarding the prevalence of depressive symptoms (Castro-Costa et al., 2007; Bromet et al., 2011).

Regarding health behaviors, visiting the doctor because of acute care has been reported in the literature to be associated with depression. In our study, visiting the doctors five times or more seemed to have a detrimental effect in both our models, any kind of depression and severe depression. This may be due to the stress of unexpected situations, as in the case of suffering from an acute disease (Kendler and Gardner,
2016). Thus, every additional visit increases that stress and emotional burden, especially in a population known for its frailty, which may help explain the bigger effect size for those with a more severe depression. This may be reinforced by the fact that patients with major depressive disorder have been shown to visit primary care centers more frequently (Garcia-Huidobro et al., 2012), and by a high prevalence of major depressive disorder in emergency departments. (Castilla-Puentes et al., 2008) In this regard, the results must be carefully considered, keeping in mind a possible reversed causality between depression and every additional visit, where every additional visit would increase the depression and reversely, this depression may increase the conditions for more visits. On the other hand, we found that every additional day of physical exercise decreased the likelihood of being depressed by nearly $20 \%$. This beneficial effect has been reported in older populations (Tse et al., 2015) and has shown to reflect better physical functioning, higher levels of independence, decreased perception of pain, among others.

Regarding social conditions, living alone, which has been widely documented to be related to depression, was significant in model one, for any kind of depression, but not for those severely depressed. Although it may seem counterintuitive, the cross-sectional nature of this study precludes further analyses. It may be that those with more severe depression stop living alone, or the effect becomes negligible past a threshold of severity, for reasons beyond the scope of these data. On the other hand, feeling uncomfortable with their living arrangement (Singh and Misra, 2009) is statistically significant in both models, any kind of depression and severe depression, putting emphasis on the self-perception of comfort with life choices. Additionally, in the literature, feeling discriminated affected depression (Nadimpalli et al., 2015) as 
Table 3. Bivariate analysis of depression and independent variables

\begin{tabular}{|c|c|c|c|c|c|c|}
\hline & \multicolumn{2}{|c|}{ NOT DEPRESSED } & \multicolumn{2}{|c|}{ DEPRESSED } & \multirow[b]{2}{*}{ TOTAL } & \multirow[b]{2}{*}{$P$-VALU } \\
\hline & $\mathrm{N}$ & $\%$ & $\mathrm{~N}$ & $\%$ & & \\
\hline \multicolumn{7}{|c|}{ Health behavior } \\
\hline \multicolumn{7}{|c|}{ Number of visits to the doctor because of a health checkup } \\
\hline 0 times & 96.0 & 54.2 & 81.0 & 45.8 & 177.0 & 0.948 \\
\hline $1-2$ times & 111.0 & 55.2 & 90.0 & 44.8 & 201.0 & \\
\hline 3-4 times & 67.0 & 57.8 & 49.0 & 42.2 & 116.0 & \\
\hline 5 or more times & 81.0 & 55.5 & 65.0 & 44.5 & 146.0 & \\
\hline \multicolumn{7}{|c|}{ Number of visits to the doctor because of a disease } \\
\hline 0 times & 256.0 & 60.1 & 170.0 & 39.9 & 426.0 & 0.002 \\
\hline $1-2$ times & 66.0 & 50.0 & 66.0 & 50.0 & 132.0 & \\
\hline 3-4 times & 23.0 & 46.9 & 26.0 & 53.1 & 49.0 & \\
\hline 5 or more times & 10.0 & 30.3 & 23.0 & 69.7 & 33.0 & \\
\hline \multicolumn{7}{|c|}{ Physical activity per week in the past three months } \\
\hline Number of days & 0.5 & 1.5 & 0.3 & 1.2 & 617.0 & 0.146 \\
\hline \multicolumn{7}{|l|}{ Tobacco smoking } \\
\hline Never smoked & 243.0 & 59.4 & 166.0 & 40.6 & 409.0 & 0.038 \\
\hline Quitted smoking & 84.0 & 48.3 & 90.0 & 51.7 & 174.0 & \\
\hline Continues smoking & 22.0 & 51.2 & 21.0 & 48.8 & 43.0 & \\
\hline \multicolumn{7}{|l|}{ Present alcohol drinking } \\
\hline No & 272.0 & 54.6 & 226.0 & 45.4 & 498.0 & 0.418 \\
\hline Yes & 83.0 & 58.5 & 59.0 & 41.5 & 142.0 & \\
\hline \multicolumn{7}{|l|}{ Social conditions } \\
\hline \multicolumn{7}{|l|}{ House ownership } \\
\hline No & 33 & 56.9 & 25 & 43.1 & 58 & 0.955 \\
\hline Yes & 278 & 56.5 & 214 & 43.5 & 492 & \\
\hline \multicolumn{7}{|l|}{ Did you work in agriculture } \\
\hline Did not work in agriculture & 181 & 54.4 & 152 & 45.6 & 333 & 0.858 \\
\hline Worked in agriculture & 60 & 56.6 & 46 & 43.4 & 106 & \\
\hline Never worked & 113 & 56.5 & 87 & 43.5 & 200 & \\
\hline \multicolumn{7}{|l|}{ White collar work } \\
\hline Worked as white collar & 7 & 63.6 & 4 & 36.4 & 11 & 0.782 \\
\hline Work as a blue color & 234 & 54.7 & 194 & 45.3 & 428 & \\
\hline Never worked & 113 & 56.5 & 87 & 43.5 & 200 & \\
\hline \multicolumn{7}{|l|}{ Living alone } \\
\hline No & 317 & 56.8 & 241 & 43.2 & 558 & 0.075 \\
\hline Yes & 38 & 46.3 & 44 & 53.7 & 82 & \\
\hline \multicolumn{7}{|c|}{ Change of living place in the past five years } \\
\hline No & 30 & 51.7 & 28 & 48.3 & 58 & 0.547 \\
\hline Yes & 325 & 55.8 & 257 & 44.2 & 582 & \\
\hline \multicolumn{7}{|c|}{ Are you uncomfortable with your living arrangement } \\
\hline No & 345 & 57.3 & 257 & 42.7 & 602 & $<0.001$ \\
\hline Yes & 6 & 24 & 19 & 76 & 25 & \\
\hline \multicolumn{7}{|l|}{ Health insured } \\
\hline No & 17 & 65.4 & 9 & 34.6 & 26 & 0.288 \\
\hline Yes & 320 & 54.8 & 264 & 45.2 & 584 & \\
\hline Pensioned & & & & & & \\
\hline No & 112 & 58.9 & 78 & 41.1 & 190 & 0.283 \\
\hline Yes & 239 & 54.3 & 201 & 45.7 & 440 & \\
\hline Did you work last week? & & & & & & \\
\hline No & 326 & 54.5 & 272 & 45.5 & 598 & 0.067 \\
\hline Yes & 29 & 69 & 13 & 31 & 42 & \\
\hline Have you felt discriminated? & & & & & & \\
\hline No & 304 & 62 & 186 & 38 & 490 & $<0.001$ \\
\hline Yes & 51 & 34 & 99 & 66 & 150 & \\
\hline
\end{tabular}


Table 3. Continued.

\begin{tabular}{|c|c|c|c|c|c|c|}
\hline & \multicolumn{2}{|c|}{ NOT DEPRESSED } & \multicolumn{2}{|c|}{ DEPRESSED } & \multirow[b]{2}{*}{ TOTAL } & \multirow[b]{2}{*}{$P$-VALUE } \\
\hline & $\mathrm{N}$ & $\%$ & $\mathrm{~N}$ & $\%$ & & \\
\hline \multicolumn{7}{|c|}{ Do you have any recreational activity } \\
\hline No & 227 & 53.4 & 198 & 46.6 & 425 & 0.109 \\
\hline Yes & 128 & 60.1 & 85 & 39.9 & 213 & \\
\hline \multicolumn{7}{|c|}{ Do you participate in an organization? } \\
\hline No & 267 & 54.5 & 223 & 45.5 & 490 & 0.276 \\
\hline Yes & 87 & 59.6 & 59 & 40.4 & 146 & \\
\hline \multicolumn{7}{|c|}{ Do you volunteer? } \\
\hline No & 324 & 56.5 & 249 & 43.5 & 573 & 0.176 \\
\hline Yes & 30 & 47.6 & 33 & 52.4 & 63 & \\
\hline \multicolumn{7}{|c|}{ Do you receive help from an organization? } \\
\hline No & 318 & 56 & 250 & 44 & 568 & 0.460 \\
\hline Yes & 37 & 51.4 & 35 & 48.6 & 72 & \\
\hline \multicolumn{7}{|c|}{ Do you provide care to someone else? } \\
\hline No & 322 & 55.5 & 258 & 44.5 & 580 & 0.939 \\
\hline Yes & 33 & 55 & 285 & 44.5 & 60 & \\
\hline
\end{tabular}

$\chi^{2}$ with $\Phi$ coefficient for categorical variables.

$t$-test for continuous variables.

This table presents a bivariate analysis of the main outcome, divided into the depressed and not depressed groups, and the exposures, health behaviors, and social conditions.

well as mental health as a whole (Pascoe and Smart Richman, 2009), as has been found in both our models. However, to the knowledge of the authors, there are no studies dealing with ageism and mental health in Chile to discuss further and there remains a road to be explored in future research.

Regarding the association of depression and ADLs, a previous study in Santiago, the capital city of Chile, using the Survey on Health, Well-Being, and Aging in Latin America and the Caribbean (SABE) (Albala et al., 2005) focusing on older persons in Santiago and six other cities in Latin America and the Caribbean, did not find a significant association between difficulties to carry out ADLs and depression, although it did find this association in all the other six cities analyzed: Buenos Aires, Bridgetown, Sao Paulo, Habana, Mexico DF, and Montevideo. However, our model for severe depression failed to find statistical significance between ADL and severe depression.

Regarding IADLs, the same survey did not find a significant relation with depression, although it did find this association in all the other six cities analyzed mentioned above.

This lack of significance only for the Chilean sample may seem counter intuitive, as the literature shows several examples of significance between depressive symptoms and difficulties dealing with functional independence (Connolly et al., 2016). However, we can also find that the presence of high depressive symptoms may not substantially diminish physical performance (Matthews et al., 2011), making clear the cross-sectional limitation of this study. It may be argued that the present data are nationally representative, whereas the SABE survey only focused on the mainly urban capital city. It could be possible that the differences in these two settings could account for the lack of significance.

Although depression has been previously associated with poor health conditions (Philco et al., 2012), more attention should be focused on how ADLs and IADLs do relate to physical exercises in a longitudinal way. Independently, physical exercises have been shown to be an important protective factor against depression by enhancing social connections and biological markers that increase the feeling of wellbeing through physical changes that take place when doing physical activities. The present study revealed the presence of a "dose effect" between physical exercises and depression. However, the effect seems to disappear for those severely depressed, supporting the idea of encouraging physical activity to avoid depression or before depressive conditions get severe.

Mental disorders, including depressive symptoms, have been linked to smoking habits and alcohol consumption among the general adult population in Chile (Araya et al., 2007; Dois and Cazenave, 2009), but that association has not been made among older persons. In our study, there was no significant relation between smoking and alcohol drinking and depression. This may be 
Table 4. Logistic model for depression and related factors. n:557 for both models

\begin{tabular}{|c|c|c|c|c|c|c|c|c|c|c|c|c|c|c|c|c|c|}
\hline & & \multicolumn{8}{|c|}{ MODEL 1: ANY KIND OF DEPRESSSION (GDS $5>$ ) } & \multicolumn{8}{|c|}{ MODEL 2: SEVERELY DEPRESSED（GDS $10>$ ) } \\
\hline & & \multirow[b]{2}{*}{$\mathrm{B}$} & \multirow[b]{2}{*}{ S.E. } & \multirow[b]{2}{*}{ WALD } & \multirow[b]{2}{*}{ DF } & \multirow[b]{2}{*}{$\begin{array}{l}\text { P- } \\
\text { VALUE }\end{array}$} & \multirow[b]{2}{*}{$\begin{array}{l}\text { ODDS } \\
\text { RATIO }\end{array}$} & \multicolumn{2}{|c|}{$95 \%$ C.I. } & \multirow[b]{2}{*}{ B } & \multirow[b]{2}{*}{ S.E. } & \multirow[b]{2}{*}{ WALD } & \multirow[b]{2}{*}{ DF } & \multirow[b]{2}{*}{$\begin{array}{l}\text { P- } \\
\text { VALUE }\end{array}$} & \multirow[b]{2}{*}{$\begin{array}{l}\text { ODDS } \\
\text { RATIO }\end{array}$} & \multicolumn{2}{|c|}{$95 \%$ C.I. } \\
\hline & & & & & & & & LOWER & UPPER & & & & & & & LOWER & UPPER \\
\hline \multicolumn{18}{|l|}{ Health behavior } \\
\hline $\begin{array}{l}\text { Number of visits } \\
\text { for a checkup }\end{array}$ & $\begin{array}{l}\text { s to the doctors } \\
\text { (ref } 0 \text { times) }\end{array}$ & & & 2.727 & 3 & 0.436 & & & & & & 5.824 & 3 & 0.120 & & & \\
\hline & $1-2$ times & 0.114 & 0.273 & 0.173 & 1 & 0.677 & 1.120 & 0.656 & 1.912 & -0.812 & 0.414 & 3.857 & 1 & 0.050 & 0.444 & 0.197 & 0.998 \\
\hline & $3-4$ times & -0.193 & 0.322 & 0.360 & 1 & 0.548 & 0.824 & 0.438 & 1.550 & -0.068 & 0.427 & 0.026 & 1 & 0.873 & 0.934 & 0.405 & 2.156 \\
\hline & $\begin{array}{l}5 \text { or more } \\
\text { times }\end{array}$ & -0.318 & 0.315 & 1.015 & 1 & 0.314 & 0.728 & 0.392 & 1.350 & -0.742 & 0.461 & 2.595 & 1 & 0.107 & 0.476 & 0.193 & 1.174 \\
\hline \multicolumn{2}{|c|}{$\begin{array}{l}\text { Number of visits to the doctor } \\
\text { because of an acute disease } \\
\text { (ref } 0 \text { times) }\end{array}$} & & & 6.259 & 3 & 0.100 & & & & & & 7.765 & 3 & 0.051 & & & \\
\hline & $1-2$ times & 0.311 & 0.252 & 1.528 & 1 & 0.216 & 1.365 & 0.833 & 2.236 & 0.223 & 0.363 & 0.376 & 1 & 0.540 & 1.250 & 0.613 & 2.548 \\
\hline & 3-4 times & 0.511 & 0.382 & 1.790 & 1 & 0.181 & 1.668 & 0.788 & 3.527 & 0.867 & 0.481 & 3.257 & 1 & 0.071 & 2.380 & 0.928 & 6.105 \\
\hline & 5 or more & 1.052 & 0.492 & 4.565 & 1 & 0.033 & 2.862 & 1.091 & 7.511 & 1.392 & 0.571 & 5.934 & 1 & 0.015 & 4.023 & 1.313 & 12.330 \\
\hline $\begin{array}{l}\text { Chronic } \\
\text { disease }\end{array}$ & $\begin{array}{l}\text { Number of } \\
\text { chronic } \\
\text { diseases }\end{array}$ & -0.004 & 0.110 & 0.001 & 1 & 0.972 & 0.996 & 0.803 & 1.235 & 0.096 & 0.151 & 0.404 & 1 & 0.525 & 1.100 & 0.819 & 1.478 \\
\hline \multirow{3}{*}{$\begin{array}{l}\text { Smoking h } \\
\text { smoked) }\end{array}$} & t (ref Never & & & 3.444 & 2 & 0.179 & & & & & & 0.713 & 2 & 0.700 & & & \\
\hline & $\begin{array}{l}\text { Quitted } \\
\text { Smoking }\end{array}$ & 0.437 & 0.241 & 3.291 & 1 & 0.070 & 1.548 & 0.965 & 2.483 & 0.018 & 0.351 & 0.003 & 1 & 0.958 & 1.019 & 0.512 & 2.028 \\
\hline & $\begin{array}{l}\text { Continues } \\
\text { smoking }\end{array}$ & -0.007 & 0.396 & 0.000 & 1 & 0.986 & 0.993 & 0.457 & 2.157 & 0.398 & 0.480 & 0.688 & 1 & 0.407 & 1.488 & 0.581 & 3.811 \\
\hline $\begin{array}{l}\text { Physical } \\
\text { exercise }\end{array}$ & $\begin{array}{l}\text { Days doing } \\
\text { physical } \\
\text { activities in } \\
\text { the past } \\
\text { three months }\end{array}$ & -0.196 & 0.088 & 4.938 & 1 & 0.026 & 0.822 & 0.692 & 0.977 & -0.255 & 0.179 & 2.014 & 1 & 0.156 & 0.775 & 0.545 & 1.102 \\
\hline
\end{tabular}


Table 4. Continued.

\begin{tabular}{|c|c|c|c|c|c|c|c|c|c|c|c|c|c|c|c|c|}
\hline & \multicolumn{8}{|c|}{ MODEL 1: ANY KIND OF DEPRESSSION (GDS $5>$ ) } & \multicolumn{8}{|c|}{ MODEL 2: SEVERELY DEPRESSED（GDS $10>$ ) } \\
\hline & \multirow[b]{2}{*}{ B } & \multirow[b]{2}{*}{ S.E. } & \multirow[b]{2}{*}{ WALD } & \multirow[b]{2}{*}{$\mathrm{DF}$} & \multirow[b]{2}{*}{$\begin{array}{l}\text { P- } \\
\text { VALUE }\end{array}$} & \multirow[b]{2}{*}{$\begin{array}{l}\text { ODDS } \\
\text { RATIO }\end{array}$} & \multicolumn{2}{|c|}{$95 \%$ C.I. } & \multirow[b]{2}{*}{ B } & \multirow[b]{2}{*}{ S.E. } & \multirow[b]{2}{*}{ WALD } & \multirow[b]{2}{*}{$\mathrm{DF}$} & \multirow[b]{2}{*}{$\begin{array}{l}\text { P- } \\
\text { VALUE }\end{array}$} & \multirow[b]{2}{*}{$\begin{array}{l}\text { ODDS } \\
\text { RATIO }\end{array}$} & \multicolumn{2}{|c|}{$95 \%$ C.I. } \\
\hline & & & & & & & LOWER & UPPER & & & & & & & LOWER & UPPER \\
\hline \multicolumn{17}{|l|}{ Social conditions } \\
\hline $\begin{array}{l}\text { Living alone } \\
(\text { ref }=\text { with } \\
\text { others })\end{array}$ & 0.739 & 0.334 & 4.884 & 1 & 0.027 & 2.094 & 1.087 & 4.034 & 0.279 & 0.473 & 0.347 & 1 & 0.556 & 1.322 & 0.523 & 3.343 \\
\hline $\begin{array}{l}\text { Uncomfortable } \\
\text { with your } \\
\text { living } \\
\text { arrangement } \\
\text { (ref =no) }\end{array}$ & 1.301 & 0.606 & 4.607 & 1 & 0.032 & 3.671 & 1.120 & 12.039 & 1.513 & 0.632 & 5.723 & 1 & 0.017 & 4.539 & 1.314 & 15.678 \\
\hline $\begin{array}{l}\text { Living alone* } \\
\text { Uncomfort- } \\
\text { able with } \\
\text { your living } \\
\text { arrangement }\end{array}$ & 0.107 & 1.410 & 0.006 & 1 & 0.939 & 1.113 & 0.070 & 17.652 & -2.193 & 1.444 & 2.308 & 1 & 0.129 & 0.112 & 0.007 & 1.889 \\
\hline $\begin{array}{l}\text { Did you work } \\
\text { last week? } \\
\text { (ref=no) }\end{array}$ & -0.662 & 0.422 & 2.462 & 1 & 0.117 & 0.516 & 0.226 & 1.179 & -1.275 & 0.735 & 3.008 & 1 & 0.083 & 0.279 & 0.066 & 1.180 \\
\hline $\begin{array}{l}\text { Have you felt } \\
\text { discrimin- } \\
\text { ated? } \\
(\text { ref=no) }\end{array}$ & 0.807 & 0.246 & 10.759 & 1 & 0.001 & 2.240 & 1.384 & 3.628 & 1.348 & 0.323 & 17.388 & 1 & 0.000 & 3.849 & 2.043 & 7.251 \\
\hline $\begin{array}{l}\text { Have you } \\
\text { participated } \\
\text { in } \\
\text { volunteering } \\
\text { activities (ref } \\
\text { No) }\end{array}$ & 0.202 & 0.329 & 0.376 & 1 & 0.540 & 1.223 & 0.642 & 2.331 & -0.552 & 0.520 & 1.129 & 1 & 0.288 & 0.576 & 0.208 & 1.594 \\
\hline Constant & 4.229 & 1.339 & 9.976 & 1 & 0.002 & 68.621 & & & 2.604 & 1.834 & 2.017 & 1 & 0.156 & 13.518 & & \\
\hline
\end{tabular}

Notes: both models are adjusted by sex, age, urbanization, ethnic background, education in years, marital status, falls in the past years, ADL and IADL scores, pain in the past 4 weeks, hospital admission, and cognitive impairment.

This table presents a multivariable model of the factors associated to the depressed status of participants. 
due to the fact that older populations in Chile have a lower lifetime prevalence of alcohol and nicotine dependence compared to younger adult populations (Kohn et al., 2008).

Discrimination has been shown to have a harmful effect on the mental health of general Chilean population in Chile (Capezza et al., 2012). Although in Chile there are no specific studies on discrimination suffered by older persons, our results open the possibility of paying more attention to these harmful acts, keeping in mind that a depressive status may induce the perception of being discriminated.

Unemployment in Chile has been associated with poorer mental health in working age adults (Jefferis et al., 2011). However, although this relation has not been explored in older adults, we can argue that the same mechanism intervenes to account for social interactions that prevent depressive symptoms.

The present study, though being nationally representative, has some limitations that should be considered when interpreting the results. One of these limitations is the cross-sectional design of the study. Both exposure and outcome were measured at the same time, hindering the possibility of establishing causation. Although we were cautious when interpreting the results, keeping in mind the effect size, consistency, plausibility and temporality, there remained some concerns regarding reverse causality among depression and health behaviors. Additionally, the present data did not include information on the economic status of the participants, which precludes suggesting policies oriented to economic interventions. Arguably, older persons living alone, being uncomfortable with their living arrangement, and being discriminated by their socioeconomic status may be influenced by economic characteristics; however, lack of information on the subject presents a limitation in our study.

We concluded that with the decreasing number of marriages, decreased fertility rate, increased longevity, and the absence of a long-term care system, analyses on ways to support older persons living alone to avoid depression are needed. Policies reaching out to those elderly living alone should be of particular interest, along with increasing the community awareness of those living alone, and the participation of those who ostracize themselves in later stages of life.

Another aspect is the necessity to have a deeper understanding of the comfort of older persons with their living arrangement. Comfort with a living arrangement is a subjective feeling, mediated by multiple factors. Studies to analyze these mediating factors may help understand how to improve the life of those feeling uncomfortable, particularly in the absence of formal care.

Additionally, ways to prevent discrimination among older persons should be encouraged. However, it is also important to understand how this discrimination takes places and to what extent it is caused by perception or behaviors that may be classified as ageism.

Nevertheless, it must be noted that these conclusions on social conditions in the present study do not include economic characteristics, which may have a strong effect on the way depression is perceived given the present results. Further studies should address this information.

\section{Conflict of interest}

No conflict of interest was reported in this study. In addition, this study was partially supported by the Grant-in-Aid for Scientific Research of the Japan Ministry of Health, Labour and Welfare [H24Chikyukibo-ippan-001] and the 2015 Grant-in-Aid for overseas researchers under the postdoctoral fellowship of the Japan Society for the Promotion of Science (JSPS) [H27-Tokubetsu-Kenkyuin-Shoreihi]. Supporters had no role in this study.

\section{Roles of authors}

Dr. Sandoval designed the study, formulated the research question, analyzed the data and wrote the paper. Both Dr. Tamiya and Dr. Lloyd-Sherlock contributed in formulating the research question, designing the study, and interpreting the results. Dr. Haruko Noguchi helped write the paper and interpret the results.

\section{Acknowledgments}

The authors wish to thank the National Agency for Elderly People of Chile (SENAMA) for the provision of the data.

\section{References}

Albala, C. et al. (2005). The health, well-being, and aging ("SABE") survey: methodology applied and profile of the study population. Revista Panamericana de Salud Publica, 17, 307-322.

Almeida, O. P. and Almeida, S. A. (1999). Short versions of the geriatric depression scale: a study of their validity for the diagnosis of a major depressive episode according to ICD-10 and DSM-IV. International fournal of Geriatric Psychiatry, 14, 858-865. 
Araya, R., Gaete, J., Rojas, G., Fritsch, R. and Lewis, G. (2007). Smoking and common mental disorders: a population-based survey in Santiago, Chile. Social Psychiatry and Psychiatric Epidemiology, 42, 874880.

Blazer, D. G. (2003). Depression in late life: review and commentary. Fournal of Gerontology A Biological Sciences and Medical Sciences, 58, 249-265.

Bromet, E. et al. (2011). Cross-national epidemiology of DSM-IV major depressive episode. BMC Medicine, 9, 90.

Bursac, Z., Gauss, C. H., Williams, D. K. and Hosmer, D. W. (2008). Purposeful selection of variables in logistic regression. Source Code for Biology and Medicine, 3, 17.

Capezza, N. M., Zlotnick, C., Kohn, R., Vicente, B. and Saldivia, S. (2012). Perceived discrimination is a potential contributing factor to substance use and mental health problems among primary care patients in Chile. Fournal of Addiction Medicine, 6, 297-303.

Carrasco, M., Herrera, S., Fernandez, B. and Barros, C. (2013). Impact of family support on depressive complaints in the elderly in Santiago, Chile. Revista Española de Geriatría y Gerontología, 48, 9-14.

Castilla-Puentes, R. C. et al. (2008). A multicenter study of major depressive disorder among emergency department patients in Latin-American countries. Depress Anxiety, 25, E199-E204.

Castro-Costa, E. et al. (2007). Prevalence of depressive symptoms and syndromes in later life in ten European countries: the SHARE study. British fournal of Psychiatry, 191, 393-401.

Comijs, H. C. et al. (2015). The two-year course of late-life depression; results from the Netherlands study of depression in older persons. BMC Psychiatry, 15, 20.

Connolly, D., Garvey, J. and McKee, G. (2016). Factors associated with ADL/IADL disability in community dwelling older adults in the Irish longitudinal study on ageing (TILDA). Disability and Rehabilitation, 4, 1-8.

Damianovic, N. (2008). Population and society, demograpahical aspects [poblacion y sociedad, aspectos demograficos]. 52 .

Dois, C. A. and Cazenave, A. (2009). Frequency of depression among hypertensive subjects in a primary care clinic. Revista Médica de Chile, 137, 475-480.

Doraiswamy, P. M., Khan, Z. M., Donahue, R. M. and Richard, N. E. (2002). The spectrum of quality-of-life impairments in recurrent geriatric depression. fournals of Gerontology A Biological Sciences and Medical Sciences, 57, M134-M137.

Ganatra, H. A., Zafar, S. N., Qidwai, W. and Rozi, S. (2008). Prevalence and predictors of depression among an elderly population of Pakistan. Aging $\mathcal{E}$ Mental Health, 12, 349-356.

Garcia-Huidobro, D., Leon, T., Vidal, G., Poblete, F. and Rojas, P. (2012). Increased morbidity and use of primary care medical services in patients with major depressive disorder and their families: a retrospective cohort study. Atención Primaria, 44, 471-477.

Garcia-Pena, C. et al. (2008). Depressive symptoms among older adults in Mexico City. Fournal of General Internal Medicine, 23, 1973-1980.

Gitlin, L. N. and Fuentes, P. (2012). The Republic of Chile: an upper middle-income country at the crossroads of economic development and aging. Gerontologist, 52, 297-305.

Gonzalez, F. M. T. et al. (2009). National study of the dependency in older persons. In M. Center (Ed.) (p. 120). Santiago: SENAMA.

Jefferis, B. J. et al. (2011). Associations between unemployment and major depressive disorder: evidence from an international, prospective study (the predict cohort). Social Science \& Medicine, 73, 16271634.

Kendler, K. S. and Gardner, C. O. (2016). Depressive vulnerability, stressful life events and episode onset of major depression: a longitudinal model. Psychological Medicine, 46, 1865-1874.

Kohn, R., Vicente, B., Saldivia, S., Rioseco, P. and Torres, S. (2008). Psychiatric epidemiology of the elderly population in Chile. American fournal of Geriatric Psychiatry, 16, 1020-1028.

Liu, C. Y. et al. (1997). Depressive disorders among older residents in a Chinese rural community. Psychological Medicine, 27, 943-949.

Matthews, M. M., Hsu, F. C., Walkup, M. P., Barry, L. C., Patel, K. V. and Blair, S. N. (2011). Depressive symptoms and physical performance in the lifestyle interventions and independence for elders pilot study. fournal of the American Geriatrics Society, 59, 495500.

Mickey, R. M. and Greenland, S. (1989). The impact of confounder selection criteria on effect estimation. American fournal of Epidemiology, 129, 125-137.

Nadimpalli, S. B., James, B. D., Yu, L., Cothran, F. and Barnes, L. L. (2015). The association between discrimination and depressive symptoms among older African Americans: the role of psychological and social factors. Experimental Aging Research, 41, 1-24.

Palloni, A., Pinto-Aguirre, G. and Pelaez, M. (2002). Demographic and health conditions of ageing in Latin America and the Caribbean. International fournal of Epidemiology, 31, 762-771.

Pascoe, E. A. and Smart Richman, L. (2009). Perceived discrimination and health: a meta-analytic review. Psychological Bulletin, 135, 531-554.

Philco, L. P., Seron, S. P., Munoz, N. S., Navia, B. P. and Lanas, Z. F. (2012). Risk factors for metabolic syndrome in a case control study in Temuco, Chile. Revista Medica de Chile, 140, 334-339.

Saldivia, S., Vicente, B., Kohn, R., Rioseco, P. and Torres, S. (2004). Use of mental health services in Chile. Psychiatric Services, 55, 71-76.

Sheikh, J. I. (1986). Geriatric depression scale (GDS): recent evidence and development of a shorter version. Clinical Gerontologist, 5, 165-173.

Singh, A. and Misra, N. (2009). Loneliness, depression and sociability in old age. Industrial Psychiatry fournal, 18, 51-55.

Tapia, P. C. et al. (2010). Cross sectional geriatric assessment of free living older subjects from Antofagasta, Chile. Revista médica de Chile, 138, 444-451.

Tse, A. C., Wong, T. W. and Lee, P. H. (2015). Effect of low-intensity exercise on physical and cognitive health in older adults: a systematic review. Sports Medicine Open, 1, 37. 
United Nations Department of Economic and Social Affairs, P. D. (2014). World Population Ageing 2013.

Vicente, B. et al. (2006). Regional differences in psychiatric disorders in Chile. Social Psychiatry and Psychiatric Epidemiology, 41, 935-942.

Whiteford, H. A. et al. (2013). Global burden of disease attributable to mental and substance use disorders: findings from the Global Burden of Disease Study 2010. Lancet, 382, 1575-1586.
Wong, R., Pelaez, M. and Palloni, A. (2005). Selfreported general health in older adults in Latin America and the Caribbean: usefulness of the indicator. Revista Panamericana de Salud Publica, 17, 323332.

Yesavage, J. A. et al. (1982). Development and validation of a geriatric depression screening scale: a preliminary report. Fournal of Psychiatric Research, 17, 3749. 